\title{
Spectrum of Diseases, Disease Related Mortality and Overall Financial Burden of Hospitalized Patients in Medical Wards of Tertiary Care Public Hospital
}

\author{
Iftikhar Haider Naqvi, Khalid Mahmood, Abu Talib, Syed Muhammad Kashif, Ali Sajjad \\ Department of Medicine, Dow University of Health Sciences, Karachi, Pakistan \\ Email: drihnaqvi@gmail.com
}

How to cite this paper: Naqvi, I.H., Mahmood, K., Talib, A., Kashif, S.M. and Sajjad, A. (2017) Spectrum of Diseases, Disease Related Mortality and Overall Financial Burden of Hospitalized Patients in Medical Wards of Tertiary Care Public Hospital. Open Journal of Epidemiology, 7, 337-348.

https://doi.org/10.4236/ojepi.2017.74028

Received: September 30, 2017

Accepted: October 29, 2017

Published: November 1, 2017

Copyright (c) 2017 by authors and Scientific Research Publishing Inc. This work is licensed under the Creative Commons Attribution International License (CC BY 4.0).

http://creativecommons.org/licenses/by/4.0/

\begin{abstract}
Background: Detailed assessment of pattern of diseases and trend of mortalities tends to aid in formulating pivotal aspects of in-hospital policies, standards of care and so consequently promoting efficient work system. This also reserves limited resources keeping within the limit of financial grasp. The study aims to reimburse the colossal paucity of data covering epidemiological burden of diseases, impact on mortality as well as financial burden in socioeconomically challenged public health system. Methods: This was a retrospective cross-sectional hospital based study conducted in department of Medicine, Civil Hospital Karachi, from February 2016 to July 2016 using questionnaire based data collection system. Results: Eight thousand and fifty three (8053) cases with almost equal gender proportion were analyzed. Chronic liver disease (CLD) was the most rampant disease, followed by cerebrovascular accident (CVA), tuberculosis and diabetes. Overall $51 \%$ cases were attributed to infectious diseases. Overall the average percentage mortality was found to be $20 \%$ of all cases. Mean duration of stay was $7.56 \pm 7$ days. Estimated average total in-hospital expenditure per patient on each visit or stay was $159.15 \pm$ 41.2 \$USD (16670.96 \pm 4315.7 PKR). Average total diagnostic and medications costs per visit or stay were $89.74 \pm 31.2$ \$USD (9400.26 $\pm 3268.2 \mathrm{PKR})$ and $48.68 \pm 18.0$ \$USD $(5099.23 \pm 1885.5$ PKR) respectively. Conclusion: Chronic liver disease, cerebrovascular accident and diabetes were most frequent reasons of hospital admission and mortality. Recognition of most common and fatal diseases with their expenditure is going to lead to formulation of targeted policies both of which would be effective and efficient.
\end{abstract}




\section{Keywords}

Communicable Diseases, Mortality, Health Economics, Epidemiology, Infectious Diseases

\section{Introduction}

Pattern of diseases varies considerably across the globe, as well as among geographically proximate zones [1]. The earlier assumed hypothetical border between developed and developing countries, bearing respectively, non-communicable and communicable diseases, has faded [2]. Developing countries have also started to show outspreading trend of non-infectious diseases such as diabetes and hypertension as significant burden of mortality and morbidity. It can be attributed secondary to improvements in socio-economic status, acquisition of westernized diet pattern, better sanitation and immunization at least in the elite sub-population [3]. Additionally, studies have shown that malnutrition and infection in early life increase the risk of chronic non-communicating diseases in later life [4]. On other hand, developed countries are still at combat with contagious diseases with ever increasing uprisings of new trends of infections like HIV, Congo and Zika virus.

Detailed assessment of pattern of diseases and trend of mortalities tends to aid in formulating pivotal aspects of in-hospital policies and standards of care consequently promoting efficient work system which reserves limited resources within limit of financial grasp [5] [6]. In addition, it is unfortunate that such imperfect health related policies mainly abstain from the curative goals shouldering heavy burdens of finances directed towards treatment of disease itself as well as its complications. This situational catastrophe leaves little attention towards preventive strategies that can withhold disease before it's acquired. Such problems can only be dealt with issue identification in form of comprehensive data collection and evaluation at intra-unit and inter-unit levels of health facilities.

At least two third of Pakistan population is living under poverty line (US\$1) [7]. WHO recommends and promotes its member states to spend at least 5\% of gross domestic product (GDP) to achieve health related goals set by nations [8]. Whereas Pakistan government is spending $<3 \%$ of its gross domestic product (GDP) on its health finance [9]. With such scarce resources, public sector hospitals such as Civil Hospital Karachi, the largest tertiary care public sector in the province itself needs firm financial policy to provide proficient health facilities to the masses with limited budget.

The policy needs to be built upon concrete data that points towards major health related concerns and their respective financial prerequisites. Regrettably, there is colossal paucity of data covering epidemiological burden of diseases and 
their impact on mortality as well as quality of life in developing countries [10] [11]. Anticipating the lack of proper data, we carried out this study in order to compile data regarding epidemiology of top most diseases in our locality including most frequently occurring diseases and causes of mortality along with the demographic data and financial burden of the diseases over our health system. The dispersion of health insurance systems in Pakistan is scanty. This indicates the magnitude of economic concerns in health care. The study would confidently express our concerns regarding swift and imperative policy making to counteract challenges of ill health.

\section{Materials and Methods}

\subsection{Study Design}

This was a retrospective cross-sectional hospital based study conducted in Civil Hospital Karachi, the largest public sector tertiary care hospital of Pakistan from February 2016 to July 2016. All patients of either gender or any age group admitted from $1^{\text {st }}$ January 2010 till $31^{\text {st }}$ December 2015 were included in study as per consecutive sampling method technique.

\subsection{Data Collection}

A well designed patient data collection form was developed and used for this study. The data collection form was developed by consulting Physicians and staffs of pharmacology department. The following information like patient demographic details (name, age, reason for hospitalization, duration of illness, smoking history, etc), direct medical costs (drug used, laboratory tests, hospital charges) and direct non-medical costs (diet charges, other expenses) was collected From a well designed patient data collection form was developed and used for this study. The data collection form was developed by consulting Physicians and staffs of pharmacology department. All data were retrieved from record room through structured proformas directed or approved by director of the department. The proforma included demographic details (bio data, reason for admission, duration of stay) as well as year wise depiction of the mortality trend. Data related to direct medical and indirect medical cost were also recorded for expenditure analysis.

\subsection{Inclusion/Exclusion Criteria}

All non-ICU cases of any diagnosis, any age group and either gender admitted to medical unit during January 2010 to December 2015 were included in the study. Readmissions by same patients were analyzed as separate or new admission to minimize analytical difficulties.

\subsection{Disease Classification}

The classifications of diseases into communicable and non-communicable cate- 
gories were based on the definitions used by the Centers for Disease Control and Prevention and the WHO [12] [13].

\subsection{Cost Analysis}

The plan of the cost analysis was to calculate the average cost of an admission and included all costs for each admission. Expenses were assessed in Pakistani Rupees (PKR) as well as in United States dollar (\$USD) for reference comparison keeping 1 \$USD equal to 104.75 Pakistani rupees (PKR) as per national exchange rates on 10/20/2016 according to national exchange currency rate.

\section{1) Direct medical cost}

Direct medical costs included inpatient care (hospitalization), medications, medical services like laboratory tests and non-medical assecories e.g. syringes, intravenous drips, oxygen/nebulizer masks etc. Cost had been determined from day of admission till discharge although costs of medicine on discharge were excluded. As the Civil Hospital Karachi is a tertiary care hospital offering public service based facilities, so, the consultation fees, procedure fees (both major/minor), bed occupancy charges were also excluded in final cost analysis.

\section{2) Indirect medical cost}

Meal and other miscellaneous expenses were not determined. As food is provided free to all admitted patients in this tertiary care setting, its expense was not included.

\subsection{Statistical Analysis}

Data were analyzed on SPSS v.19.0, using simple qualitative and quantitative statistics and were later formulated as comprehensive tables.

\section{Results}

The study reveals a total number of 8053 cases of patients who were admitted to medical unit 1 during the course of five years. Male to female proportion was almost symmetrical with 4228 (52.50\%) males and 3825 (47.50\%) females. The male to female ratio was of 1.1:1. Average age of patients was $43.6 \pm 18.2$ years where the most patients belonged to the 41 to 50 years age group.

The detailed analysis of data revealed large variety of diagnoses, which were compacted into workable top 20 diagnoses. The realm of these diagnoses have been mentioned in Table 1 and Figure 1, showing chronic liver disease (CLD) (secondary to viral hepatitis $93.20 \%$ versus non-viral 6.80\%) to be the most rampant disease followed by cerebrovascular accident (CVA) (54\% hemorrhagic stroke versus $42.0 \%$ ischemic stroke versus $3.6 \%$ TIAs), pulmonary/extra-pulmonary tuberculosis and diabetes with its microvascular and macro vascular complications. Overall $51 \%$ cases were attributed to infectious diseases. Overall mortality was constituted $20.0 \%$ of all cases. Mean duration of stay was $7.56 \pm 7$ days. Minimum and maximum duration of stay ranged from 0 to 60 days with majority (46.60\%) of patients being discharged within a lapse of week. 


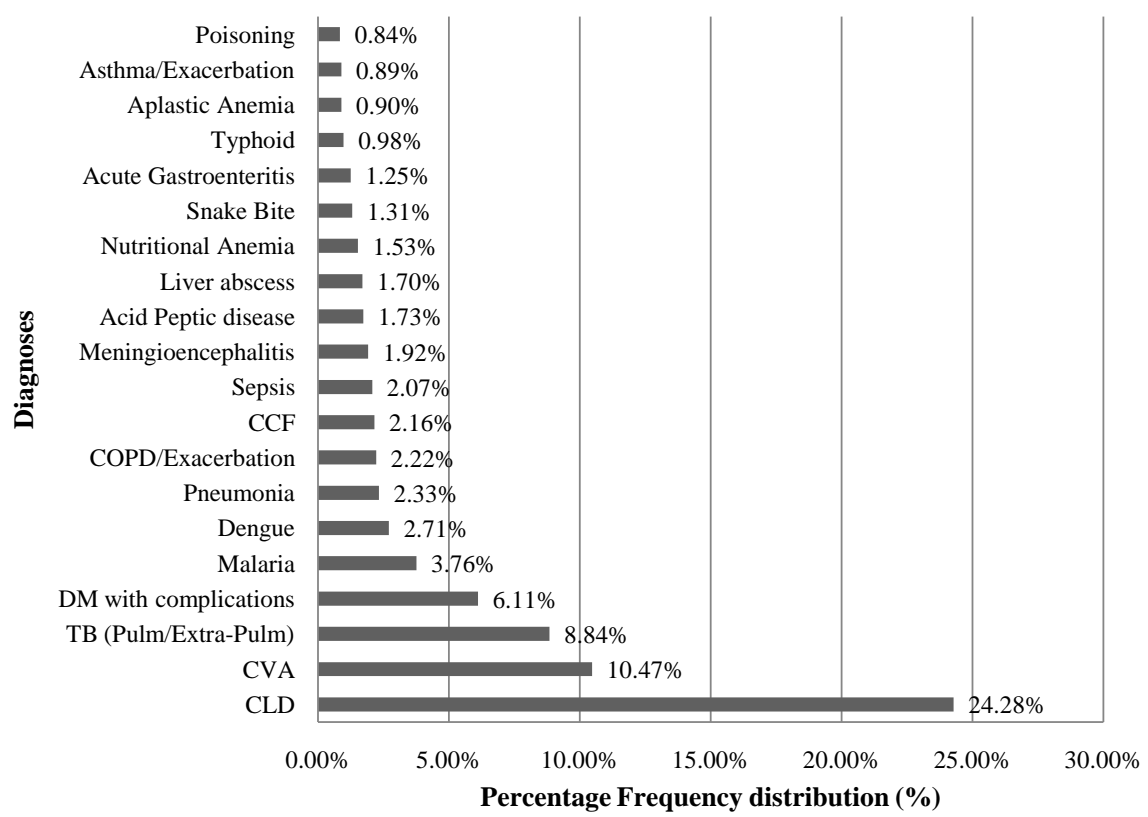

Figure 1. Distribution pattern of diseases.

Table 1. Diseases frequency and mortality.

\begin{tabular}{|c|c|c|c|c|c|c|c|c|c|}
\hline S. No & Diagnoses & Frequency & Percent & $\begin{array}{c}\text { No. of } \\
\text { Expiries }\end{array}$ & $\begin{array}{c}\% \\
\text { Mortality }\end{array}$ & $\begin{array}{c}\text { Avg. } \\
\text { Duration of Stay }\end{array}$ & $\begin{array}{l}\text { Std. } \\
\text { Dev. }\end{array}$ & Min & $\operatorname{Max}$ \\
\hline 1 & Chronic Liver Disease & 1955 & $24.3 \%$ & 501 & $25.63 \%$ & 7.58 & 6.919 & 0 & 42 \\
\hline 2 & Cerebrovascular Accident & 843 & $10.5 \%$ & 179 & $21.23 \%$ & 7.13 & 6.13 & 0 & 48 \\
\hline 3 & $\begin{array}{c}\text { Tuberculosis } \\
\text { (Pulmonary/Extra-Pulmonary) }\end{array}$ & 712 & $8.8 \%$ & 127 & $17.84 \%$ & 9.03 & 8.585 & 0 & 52 \\
\hline 4 & Diabetes with Complications & 492 & $6.1 \%$ & 98 & $19.92 \%$ & 9.39 & 8.304 & 0 & 60 \\
\hline 5 & Malaria & 303 & $3.8 \%$ & 70 & $23.10 \%$ & 6.16 & 5.526 & 0 & 38 \\
\hline 6 & Dengue & 218 & $2.7 \%$ & 36 & $16.51 \%$ & 4.7 & 3.976 & 0 & 20 \\
\hline 7 & Pneumonia & 188 & $2.3 \%$ & 42 & $22.34 \%$ & 6.56 & 5.586 & 0 & 26 \\
\hline 8 & $\begin{array}{l}\text { Chronic Obstructive } \\
\text { pulmonary Disease }\end{array}$ & 179 & $2.2 \%$ & 47 & $26.26 \%$ & 6.89 & 5.73 & 0 & 32 \\
\hline 9 & Congestive Cardiac Failure & 174 & $2.2 \%$ & 42 & $24.14 \%$ & 8.15 & 7.294 & 0 & 34 \\
\hline 10 & Sepsis & 167 & $2.1 \%$ & 45 & $26.95 \%$ & 7.04 & 8.255 & 0 & 42 \\
\hline 11 & Meningioencephalitis & 155 & $1.9 \%$ & 28 & $18.06 \%$ & 9.01 & 7.592 & 0 & 39 \\
\hline 12 & Acid Peptic Disease & 139 & $1.7 \%$ & 20 & $14.39 \%$ & 5.5 & 4.743 & 0 & 30 \\
\hline 13 & Liver Abscess & 137 & $1.7 \%$ & 22 & $16.06 \%$ & 7.24 & 7.249 & 0 & 34 \\
\hline 14 & Nutritional Anemia & 123 & $1.5 \%$ & 29 & $23.58 \%$ & 8.88 & 7.93 & 0 & 35 \\
\hline 15 & Snake Bite & 106 & $1.3 \%$ & 18 & $16.98 \%$ & 3.48 & 2.687 & 0 & 14 \\
\hline 16 & Acute Gastroenteritis & 101 & $1.3 \%$ & 19 & $18.81 \%$ & 6.05 & 7.915 & 0 & 37 \\
\hline 17 & Typhoid & 79 & $1.0 \%$ & 17 & $21.52 \%$ & 7.04 & 8.255 & 0 & 42 \\
\hline 18 & Aplastic Anemia & 73 & $0.9 \%$ & 15 & $20.55 \%$ & 6.36 & 4.692 & 0 & 18 \\
\hline 19 & Asthma/Exacerbation & 72 & $0.9 \%$ & 7 & $9.72 \%$ & 6.13 & 3.947 & 1 & 22 \\
\hline \multirow[t]{2}{*}{20} & Poisoning & 67 & $0.8 \%$ & 15 & $22.39 \%$ & 2.9 & 2.503 & 0 & 8 \\
\hline & Total & 8053 & $100.0 \%$ & 1659 & $20.60 \%$ & 7.56 & 7.02 & 0 & 60 \\
\hline
\end{tabular}


A year wise pattern of disease appears to have remained stable and predictable. Likewise, trends of mortality corresponded to majority of the cases admitted to the wards with same above mentioned diseases being most common cause of lethality. There was no specific pattern of variability of diseases and mortality in cases during the course of five years as projected in Figure 2.

In-hospital expenses in term of diagnoses, medications and nonmedical expenditures were estimated and expressed in terms of United States Dollar (\$USD), as shown in Table 2, while expenditure in local currency i.e. Pakistani Rupees (PKR) have also been mentioned here for brief comparison. Estimated average total in-hospital expenditure per patient per visit or stay was $159.15 \pm$ 41.2 \$USD (16670.96 \pm 4315.7 PKR). Average total diagnostic and medications costs per visit or stay were 89.74 \pm 31.2 \$USD $(9400.26 \pm 3268.2 \mathrm{PKR})$ and 48.68 \pm 18.0 \$USD $(5099.23 \pm 1885.5 \mathrm{PKR})$ respectively. Highest expenses were spent in patients with CLD 265.9 \pm 61.0 SUSD (27853.50 \pm 6389.75 PKR), followed by meningoencephalitis $258.83 \pm 51.1$ \$USD $(27112.60 \pm 5352.72 \mathrm{PKR})$ and diabetes with its directly related complications $221.86 \pm 39.1$ \$USD (23337.32 \pm 4095.72 PKR).

Table 2. Financial burden (in United States Dollar \$USD).

\begin{tabular}{|c|c|c|c|c|c|}
\hline S. No. & Diagnoses & $\begin{array}{c}\text { Diagnostic } \\
\text { Cost } \\
\text { (\$USD) }\end{array}$ & $\begin{array}{l}\text { Medication } \\
\text { Cost } \\
(\$ U S D)\end{array}$ & $\begin{array}{c}\text { Non-Medication } \\
\text { Cost (Assecories) } \\
\text { (\$USD) }\end{array}$ & $\begin{array}{c}\text { Total } \\
\text { (\$USD) }\end{array}$ \\
\hline 1 & Chronic Liver Disease & 138.53 & 108.26 & 19.11 & 265.90 \\
\hline 2 & Cerebrovascular Accident & 163.86 & 21.71 & 19.27 & 204.84 \\
\hline 3 & $\begin{array}{c}\text { Tuberculosis } \\
\text { (Pulmonary/Extra-Pulmonary) }\end{array}$ & & 30.22 & 22.44 & 157.51 \\
\hline 4 & Diabetes with Complications & 164.12 & 30.60 & 21.39 & 216.11 \\
\hline 5 & Malaria & 57.00 & 8.31 & 21.98 & 87.29 \\
\hline 6 & Dengue & 50.61 & 0.27 & 17.05 & 67.93 \\
\hline 7 & Pneumonia & 66.07 & 45.45 & 14.82 & 126.34 \\
\hline 8 & $\begin{array}{l}\text { Chronic Obstructive } \\
\text { Pulmonary Disease }\end{array}$ & 84.26 & 64.81 & 17.67 & 166.74 \\
\hline 9 & Congestive Cardiac Failure & 99.00 & 19.74 & 18.16 & 136.91 \\
\hline 10 & Sepsis & 85.06 & 91.65 & 20.09 & 196.80 \\
\hline 11 & Meningioencephalitis & 106.97 & 161.25 & 18.39 & 286.61 \\
\hline 12 & Acid Peptic Disease & 77.42 & 35.13 & 21.39 & 133.94 \\
\hline 13 & Liver Abscess & 74.54 & 66.16 & 20.82 & 161.52 \\
\hline 14 & Nutritional Anemia & 91.36 & 6.92 & 18.70 & 116.98 \\
\hline 15 & Snake Bite & 55.50 & 110.46 & 21.21 & 187.17 \\
\hline 16 & Acute Gastroenteritis & 85.84 & 19.94 & 12.95 & 118.73 \\
\hline 17 & Typhoid & 63.65 & 25.86 & 16.81 & 106.32 \\
\hline 18 & Aplastic Anemia & 94.33 & 7.91 & 18.33 & 120.57 \\
\hline 19 & Asthma/Exacerbation & 72.75 & 57.00 & 17.35 & 147.10 \\
\hline 20 & Poisoning & 39.14 & 39.68 & 16.99 & 95.82 \\
\hline
\end{tabular}




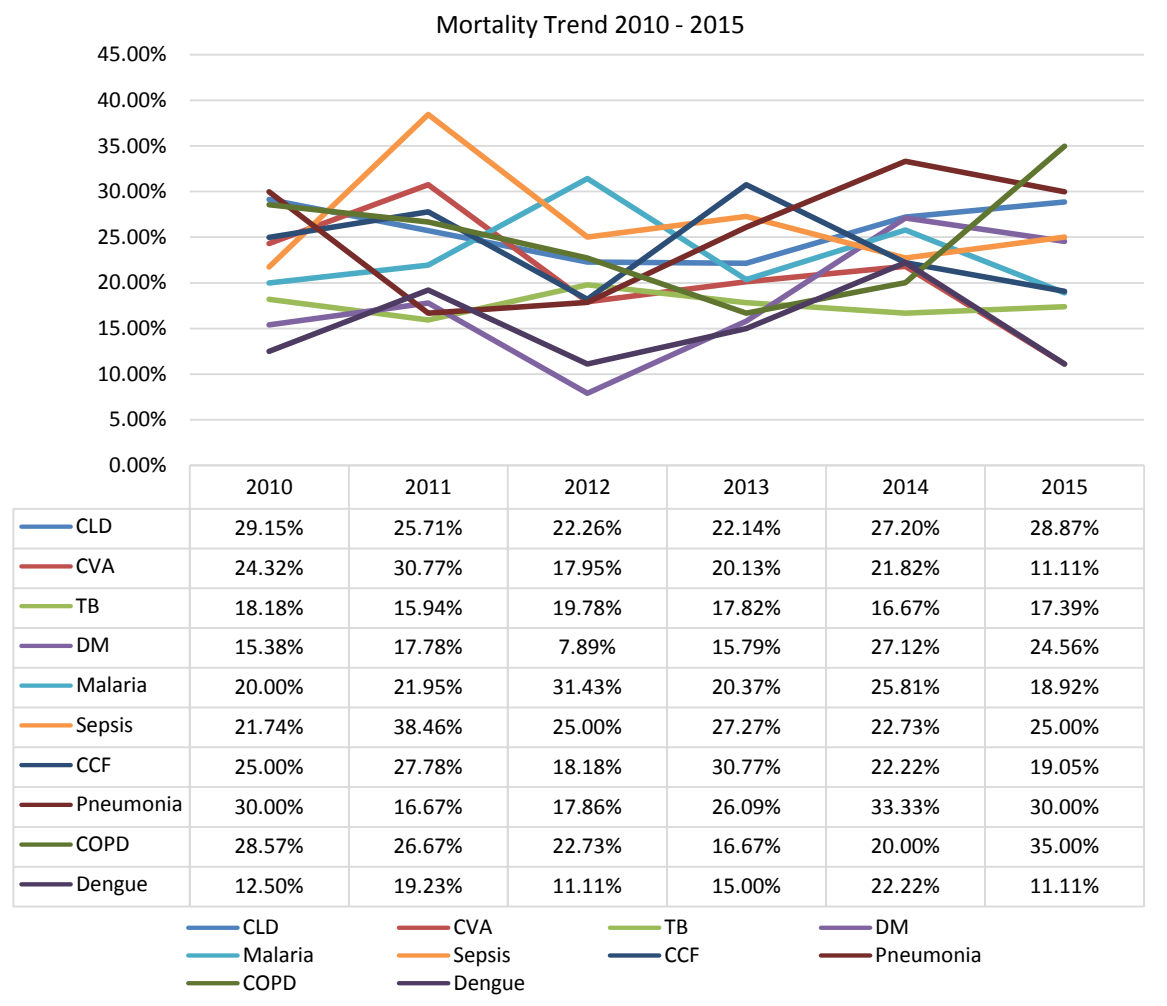

Figure 2. Mortality trends of different diseases in 5 years.

\section{Discussion}

Nature of cases a hospital receives may vary according to the geographical location of hospital, degree of urbanization of surrounding, availability of facilities on level of sub-specialty and ease of public transport. The study enlightens usual arrays of diseases being encountered by the public hospital receiving an ever hefty burden of patients from both urban and rural populations of representative city of Pakistan. Though local issues like snake bite, organophosphate poisoning (accidental/suicidal) and liver abscess also contribute in top 20 illnesses, there is an increasing trend of non-communicable diseases slowly encroaching over communicable ones towards top priority issues.

Overall $51 \%$ of cases could be attributed to infections in this study which are relatively higher than $31 \%$ and $43 \%$ respectively reported by Pokharel et al. and Haitham et al. [14] [15]. With somewhat contradictory to our study pattern, an earlier Nepalese study showed chronic obstructive pulmonary disease (COPD) being the most common disease followed by UTI, pneumonia, poisoning, enteric fever, acute gastroenteritis and hypertension [14]. While later a Sudanese study revealed that gastroenteritis was responsible for $24.4 \%$ of all gastrointestinal diseases followed by pneumonia, stroke, hypertension, malaria and diabetes [15]. The different patterns of diseases in different studies indicate their local prevalence.

Despite an earlier research [16] showing chronic liver disease as the most representative disease of gastroenterology system, the epidemiologic contributions 
of chronic liver disease in these studies seemed veiled in shade of other diagnoses. However, a local study from Faisalabad reported chronic liver disease to be the second most frequent reason for hospital admission, which was superseded by diabetes with complications [17]. Similarly Almoudi et al. reported diabetes to be most frequent diagnosis with chronic liver disease as fourth most locally prevalent disease [18]. Most likely explanation for chronic liver disease being the topmost disease lies not only in high prevalence of chronic viral hepatitis but also in possible readmission of the same patients time and again because of progressively complicating course of illness.

In contrast to the present study, a Nigerian study showed cardiovascular diseases to be most frequent reason for hospital admission with cardiovascular system being involved in $32 \%$ of cases [19]. Similar results were found in studies conducted in Australia and Hong Kong which reported cardiovascular system being involved in $29 \%$ and $30.3 \%$ of cases admitted to medical ward respectively [20]. This study could not find any considerable change to be reported in pattern of disease throughout 5 years probably because of lack of positive evolution in life style of general population and lack of introduction of any revolutionary diagnostic/therapeutic reform for any disease to significantly alter any disease pattern.

The verity that males slightly predominated in case enrolment as compared to females, was a divisive addition to literature since different studies depict different statistics regarding gender [15] [17] [18] [21]. Age group analysis revealed almost parabolic distribution, as most frequent age group was 41 to 50 years with either side of 10 years group being second most common age groups. Only $15 \%$ patients admitted in medical ward belonged to age group of over 61 years which was probably because of lower life expectancy in the region. With exception of Elias et al. which reported as 21 to 30 years age group to be the most frequently involved age group, most researchers report similar or relatively older age group cases i.e. (>45 years) in contemporary studies [14] [16] [17]. Majorly in different to researches, length of patients stay at ward was less than 7 days (61\%), however, in our study average length of stay was slightly higher than reported by certain other researches [14] [15] [18].

Regrettably, overall mortality in our study, reported as 1 case for each 5 patient, was significantly higher than many other local studies where the figures were $1.6 \%, 6.2 \%$ and $12.05 \%$ respectively [22] [23] [24]. Notably there was no noteworthy variation in array of deaths with general pattern of diseases from 2010 till 2015. Most frequent diseases as well as causes of expiry had similar pattern that is chronic liver disease followed invariably by cerebrovascular accidents, tuberculosis, complicated diabetes and malaria.

An earlier conducted local study revealed chronic liver disease, cerebrovascular accident and ischemic heart disease to be the most likely causes of death in decreasing order [25]. CLD and CVA were also top most deadly diseases depicted by two researches conducted earlier in Karachi [25] [26]. Latter study also reported respiratory illnesses, tuberculosis, cardiac diseases, infections, diabetes 
and meningitis to be additional causes of death quite similar to our research. Contrastingly, the studies carried out in economically privileged countries reflected expiries secondary to cardiovascular disease, COPD, asthma, and malignancies to be relatively uncommon. This may be partially attributed to separate sub-specialty units in Civil Hospital Karachi, dealing respective cases of cardiology and oncology [27] [28] [29].

Considering health economics, a Western Indian study conducted in private institution stated the cost of therapy per patient to be $260 \pm 52$ \$USD, which is significantly higher than our total medication related cost per visit/stay i.e. 48.68 \pm 18.0 \$USD (5099.23 \pm 1885.5 PKR) [30]. This higher cost per visit in above referred Indian study may be due to expenditure analysis of a private hospital rather than public sector hospital. Likewise in a Canadian study, cost per non-ICU day of medical cases were 232 \$USD which is considerably higher than our study [31]. In similar manner, an Indian study conducted at Sir Takhtsinhji General Hospital, Bhavnagar, Gujarat, estimated an average total cost of treatment per critical care unit of medical patients of about 55.87 \$USD (3121.28 INR), approximating more to our study than former ones. However, the same study stated laboratory related mean expenses of approximately 27.24 \$USD (1521.41 INR), which was far lesser than our total diagnostic cost per visit or stay i.e. 89.74 \$USD (9400.26 PKR) [32]. On contrary to all above studies including ours, a Nepalese study avowed mean drug cost per patient as 26.6 \$USD during hospital stay [33].

A Simple reason of this difference is that certain diagnostic tests including CT Scan and MRI Scan are available free of cost in Civil Hospital Karachi but many interventions including thrombolysis for CVA, Transjugular intrahepatic portosystemic shunt (TIPPS) for CLD are not. Furthermore, being public service hospital, therapeutic procedures like Ultrasound guided aspiration and Endoscopies with/without sclerotherapy/band ligations were not taken into account of financial burden.

\section{Conclusion}

The study illuminates varieties of illnesses encountered in the largest tertiary care public sector university hospital. Chronic liver disease, cerebrovascular accident and diabetes were most frequent reasons of hospital admission and mortality. Recognition of most common diseases and their expenditures lead to formulation of targeted policies which will be both effective and efficient futuristically.

\section{Limitation}

Due to huge variety of diseases taken into account in our study, we were able to focus on top 20 diagnoses leaving behind only smaller though significant portion of disease burden. Indirect medical costs, including transportation fares and patients' and or attendants' wages lost were not assessed. Readmissions by same pa- 
tients could not be precisely traced and their data were utilized as new/separate patient. This study may act as a maiden step towards researches oriented at disease burden as well as health economics.

\section{References}

[1] Pan, J.C. and Cheung, T.D. (1982) Medical and Cardio Vascular Diseases, Admission in Hong Kong Hospital. Bulletin Hong Kong Medical Association, 34, 55-62.

[2] Respiratory Diseases in Canada (2001) Canadian Institute for Health Information. Canadian Lung Association. Health Canada. Statics Canada, Ottawa, Canada, 1-102.

[3] Gaziano, T.A., Bitton, A., Anand, S. Abrahams-Gessel, S. and Murphy, A. (2010) Growing Epidemic of Coronary Heart Disease in Low- and Middle-Income Countries. Current Problems in Cardiology, 35, 72-115.

[4] Bygbjerg, I.C. (2012) Double Burden of Non Communicable and Infectious Diseases in Developing Countries. Science, 337, 1499-501. https://doi.org/10.1126/science.1223466

[5] Iezzoni, L.I. (2013) Reasons for Risk Adjustment. In: Risk Adjustment for Measuring Health Care Outcomes, Health Administration Press, Illinois, Chicago, 1-14.

[6] Singhi, S., Gupta, G. and Jain, V. (2004) Comparison of Pediatric Emergency Patients in a Tertiary Care Hospital vs. a Community Hospital. Indian Pediatrics, 41, 67-72.

[7] United Nations Development Program (2007) Human Development Report 2007/2008. Fighting Climate Change: Human Solidarity in a Divided World. UNDP, New York, 239.

[8] World Health Organization (2000) World Health Report 2000. Health Systems: Improving Performance. WHO, Geneva, 73-90.

[9] World Health Organization (2016) WHO Country Fact Sheet. World Health Organization, Geneva. Available from http://www.who.int/countries/pak/en/. Accessed: Oct 2016.

[10] Marsh, D.R., Kadir, M.M., Husein, K., Luby, S.P., Siddique, R. and Khalid, S.B. (2000) Adult Mortality in Slums of Karachi, Pakistan. Journal of the Pakistan Medical Association, 50, 300-306.

[11] Bhurgi, A., Bhurgi, Y., Khan, Y., Sharih, U., Naqvi, F. and Soomro, I.B. (2001) Mortality Statistics in South Karachi. Journal of the Pakistan Medical Association, 51, 446-449.

[12] Centers for Disease Control and Prevention. Menu of Suggested Provisions for State Tuberculosis Prevention and Control Laws: Definitions for Consideration.

[13] World Health Organization. Noncommunicable Diseases: Fact Sheet. http://www.who.int/mediacentre/factsheets/fs355/en/

[14] Pokharel, B.R., Humagain, S., Pant, P., Gurung, R., Koju, R. and Bedi, T.R. (2012) Spectrum of Diseases in a Medical Ward of a Teaching Hospital in a Developing Country. Journal of College of Medical Sciences-Nepal, 12, 7-11.

[15] Haitham, M., Bingawi, E.I., Hussein, M., Mohamed, B. and Bakheet, Y. (2014) Characteristics of Patients Admitted to Medical Ward of a Referral Hospital in a Developing Country. International Journal of Sciences. Basic and Applied Research, $14,86-92$.

[16] Ali, E. and Woldie, M. (2010) Reasons and Outcomes of Admissions to the Medical Wards of Jimma University Specialized Hospital, Southwest Ethiopia. Ethiopian 
Journal of Health Sciences, 20, 113-120.

[17] Ashraf, M. and Zakria, M. (2014) Disease Patterns: Admitted Patients in Medical Ward of Independent University Hospital, Marzipura, Faisalabad. Professional Medical Journal, 21, 570-574.

[18] Alamoudi, O.S., Attar, S.M., Ghabrah, T.M. and Al-Qassimi, M.A. (2009) Pattern of Common Diseases in Hospitalized Patients at an University Hospital in Saudi Arabia; A Study of 5594 Patients. Medical Science, 16. https://doi.org/10.4197/Med.16-4.1

[19] Ogunmola, O.J. and Oladosu, O.Y. (2014) Pattern and Outcome of Admissions in the Medical Wards of a Tertiary Health Center in a Rural Community of Ekiti State, Nigeria. Annals of African Medicine, 1, 195. https://doi.org/10.4103/1596-3519.142291

[20] E.G. (1960) Saint Medical Morbidity in a General Hospital. Medical Journal of Australia, 2, 601-608.

[21] Adeoti, A.O., Ajayi, E.A., Ajayi, A.O., Dada, S.A., Fadare, J.O., Akolawole, M., Adekeye, K.A. and Raimi, T.H. (2015) Pattern and Outcome of Medical Admissions in Ekiti State University Teaching Hospital, Ado-Ekiti-a 5 Year Review. American Journal of Medicine and Medical Sciences, 5, 92-98.

[22] Aziz, S., Ejaz, A. and Alam, S.E. (2013) Mortality Pattern in a Trust Hospital: A Hospital Based Study in Karachi. Journal of the Pakistan Medical Association, 63, 1031-1035.

[23] Tariq, M., Jafri, W., Ansari, T., Awan, S., Ali, F., Shah, M., Jamil, S., Riaz, M. and Shafqat, S. (2009) Medical Mortality in Pakistan: Experience at a Tertiary Care Hospital. Postgraduate Medical Journal, 85, 470-474. https://doi.org/10.1136/pgmj.2008.074898

[24] Rao, M.H. and Soomro, I.B. (2001) Disease Pattern, Seasonal Variation and Major Causes of Death in Indoor Patients at Medical Units of Civil Hospital, Karachi. $P J M R, 40,56-60$.

[25] Qadir, A., Nadeem, M.A., Munir, A. and Khan, Z.U. (2016) An Audit of Indoor Morbidity and Mortality in a Medical Ward at a Tertiary Care Hospital. Annals of King Edward Medical University, 11.

[26] Memon, A.R., Hussain, T. and Asfar, S. (2005) Mortality Rate in a General Medical Unit. Med Channel, 11, 49-51.

[27] (2002) Annual Health Bulletin. Department of Health Services, Sri Lanka, 22-31. http://www.heath.gov.Ik/tsumami/Links/ahb2002.html

[28] Papadopoulos, I.N., Papaefthymiou, M., Roumeliotis, L., Panagopoulos, V.G., Stefanidou, A. and Kostaki, A. (2008) Status and Perspectives of Hospital Mortality in a Public Urban Hellenic Hospital, Based on a Five-Year Review. BMC Public Health, 23, 28. https://doi.org/10.1186/1471-2458-8-28

[29] Sans, S., Kesteloot, H. and Kromhout, D.O. (1997) The Burden of Cardiovascular Diseases Mortality in Europe. European Heart Journal, 18, 1231-1248. https://doi.org/10.1093/oxfordjournals.eurheartj.a015434

[30] Shelat, P.R. and Kumbar, S.K. (2015) A Retrospective Analysis of Direct Medical Cost and Cost of Drug Therapy in Hospitalized Patients at Private Hospital in Western India. Journal of Clinical and Diagnostic Research: JCDR, 9, FC09. https://doi.org/10.7860/JCDR/2015/15121.6724

[31] Norris, C., Jacobs, P., Rapoport, J. and Hamilton, S. (1995) ICU and Non-ICU Cost per Day. Canadian Journal of Anesthesia, 42, 192-196. 
https://doi.org/10.1007/BF03010674

[32] Patel, M.K., Barvaliya, M.J., Patel, T.K. and Tripathi, C. (2013) Drug Utilization Pattern in Critical Care Unit in a Tertiary Care Teaching Hospital in India. International Journal of Critical Illness and Injury Science, 3, 250-255.

https://doi.org/10.4103/2229-5151.124128

[33] Shankar, P.R., Upadhyay, D.K., Subish, P., Bhandari, R.B. and Das, B. (2010) Drug Utilization among Older Inpatients in a Teaching Hospital in Western Nepal. Singapore Medical Journal, 5, 28-34. 